\title{
THE MONITORING SYSTEM OF INDOOR AIR QUALITY BASED ON INTERNET OF THINGS
}

\author{
Agung Pangestu ${ }^{1}$, Muhammad Yusro ${ }^{1}$, Wisnu Djatmiko ${ }^{1}$, Ariep Jaenul ${ }^{2, *}$ \\ ${ }^{1}$ Indonesia Faculty of Engineering, Universitas Negeri Jakarta, 13220, East Jakarta, DKI Jakarta, Indonesia \\ ${ }^{2}$ Department of Electrical Engineering, Faculty of Engineering and Computer Science, Institut Teknologi dan \\ Kesehatan Jakarta, 17411, Bekasi, Jawa Barat, Indonesia
}

*Corresponding Author Email: ariep@itkj.ac.id

Received: 15 June 2020

Revised: 14 August 2020

Accepted: 18 August 2020

Online: 31 August 2020

Published: 31 August 2020

SPEKTRA: Jurnal Fisika dan Aplikasinya p-ISSN: 2541-3384

e-ISSN: 2541-3392

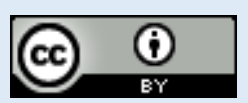

\begin{abstract}
The indoor air quality monitoring system is needed to find out good air condition. Good air condition can be seen from two (2) factors, namely dust, and temperature. Dust in a room can affect health if it exceeds the threshold of $0.15 \mathrm{mg} / \mathrm{m}^{3}$, and the temperature of $35^{\circ} \mathrm{C}$ has been determined by SK MENKLH No.02/MENKLH/I/1998. Related to that, we need a system that can determine the temperature and dust conditions in a room. The aim of this research is creating an indoor air quality monitoring system based on the Internet of Things (IoT). This research uses engineering methods, which include planning, design, testing, and system implementation. In this system, when the dust level is more than $0.15 \mathrm{mg} / \mathrm{m}^{3}$ the LED indicator 1 and the active sprayer tell and neutralize the dust content in the air and when the intensity of the temperature is more than $35^{\circ} \mathrm{C}$ the LED indicator 2 and the active sprayer tell and neutralize the temperature intensity at the room. When both values exceed the set threshold, the LED indicators 1, LED 2, buzzer, the sprayer will be active simultaneously to notify and neutralize the air and temperature in the room. The test results show this system can work well with the percentage of errors in the testing of $12 \%$ for dust sensors and $1.6 \%$ for temperature sensors.
\end{abstract}

Keywords: indoor Air Quality, dust, temperature, IoT 


\section{INTRODUCTION}

Indoor air quality refers to the pros and cons of air in the room that can affect the health of its occupants, physical reactions, comfort, and performance in doing work [1,2]. Air quality in the room is said to be good if the air contaminant content in a room does not exceed a certain level either in the form of chemicals (gas), biological (fungi or bacteria), or physical contaminants such as dust (particles; PM10, PM2.5 or ultrafine particles ) [3]. Dust is a solid particle produced by humans or nature and is the result of the process of breaking down the material of production. Dust, under certain conditions, is a chemical agent that can cause a reduction in work comfort, vision problems, impaired lung physiology, and can even cause general poisoning [4]. Besides, the temperature and humidity of the air also complement changes caused by dust such as the skin of the face, eyes, and the human body becomes dull and wrinkled easily because the dust that sticks reacts with sweat burned in the sun, triggering the development of oxidation and free radicals in it [5]. In dust, plants cover the means of photosynthesis production and chemical structure of the land, which is very disturbing growth [6]. In tool and machine technology, dust destroys beauty and function by making metal materials corrosive, moldy, and drying lubricants, plastic aging rapidly by experiencing cracks due to reacting polymers to dust particles and many changes damaged by dust [7]. The state, through the relevant ministries, determines the threshold for dust in accordance with MENKLH Decree No. Kep.02 / MENKLH / 1988 is $0.15 \mathrm{mg} / \mathrm{m}^{3}$ and temperature is $35^{\circ} \mathrm{C}$ [8]. Handling of dust is always late because there is no system that can monitor dust and temperature in real-time, coupled with the absence of action when a room exceeds a predetermined threshold [9]. For this reason, this research was done with the aim of monitoring in real-time the air quality contained in a room by looking at two factors, namely dust and temperature, and neutralizing the presence of dust when it passed a predetermined threshold.

\section{RELATED WORK}

Some researchers conduct research in the field of indoor air quality monitoring systems. A previous study created an indoor/outdoor monitoring program conducted at two university sports facilities: fronton and gymnasium [10]. This research monitors comfort parameters (temperature, relative humidity, $\mathrm{CO}_{2}$ ), $\mathrm{CO}$, and total organic volatile compounds (TVOCs). Subsequent research [11] conducted indoor air quality monitoring using the Wireless Sensor Network (WSN). This study used a modular design method, has portability and scalability, and has low production costs, real-time monitoring data, and human-machine interaction. In another study, monitoring of air quality in a classroom was carried out by [12]. This study conducted monitoring of basic parameters such as carbon dioxide, humidity, and temperature in the University of Ferrara classroom. The Low-cost Indoor Air Quality (IAQ) platform was developed by [13] and named SKOMOBO, which can monitor indoor air quality parameters such as classroom temperature, relative humidity, unique material, and carbon dioxide levels. Because this system is designed for home use and uses low-cost sensors, the costs for production are relatively low. 


\section{METHOD}

This study uses engineering methods with the Borg and Gall model, which consists of several stages as follows:

1. System Planning

2. Hardware Design

3. Software Design

4. Hardware and Software Testing

5. Testing Analysis

Furthermore, the flowchart of this study, as shown in FIGURE 1.

\section{SYSTEM PLANNING}

This research makes a prototype of an indoor air quality monitoring system based on the Internet of Things (IoT). Internet of Things (IoT) is used so that monitoring can be done by utilizing the internet network so that it can be monitored remotely using a smartphone. In addition, this system is made so that it can neutralize dust levels that exceed the threshold that has been determined based on Decree No. MENKLH No. Kep.02 / MENKLH / 1988 is 0.15 $\mathrm{mg} / \mathrm{m}^{3}$ and a temperature of $35^{\circ} \mathrm{C}$. That way, the air quality in the room is still maintained.

\section{HARDWARE DESIGN}

Hardware design is an important stage in the success of a system. The system block diagram as shown in FIGURE 2. As seen in FIGURE 2 above, the input uses two types of sensors, namely a dust sensor and temperature sensor. The dust sensor is used to detect the presence of dust in the room by using an infrared-based type GP2Y1010AU0F Optical Dust Sensor. The choice of this sensor is because it is very effective in detecting very fine particles such as dust or cigarette smoke, and is generally used for air purification systems [14]. As for the temperature sensor using the DHT 22 type, this sensor is used to measure temperature and relative humidity with an output in the form of a digital signal. DHT 22 was chosen because it has better accuracy than DHT 11 [15].

Next, the control system uses the Arduino Mega 2560. Arduino selection is made because it has several advantages such as not needing a programmer chip device because it has a bootloader that can handle programs uploaded from a computer and programming language is relatively easy [16]. Furthermore, for Arduino to be connected to the internet, it requires Arduino Ethernet Shield. This module is based on Wiznet W5100. Wiznet W5100 is a provider (IP) network that supports TCP and UDP [17]. The Arduino ethernet shield module is connected to the internet by connecting to the router. The router functions here as a bridge so that Arduino can be controlled via the internet using a mobile web (smartphone). 


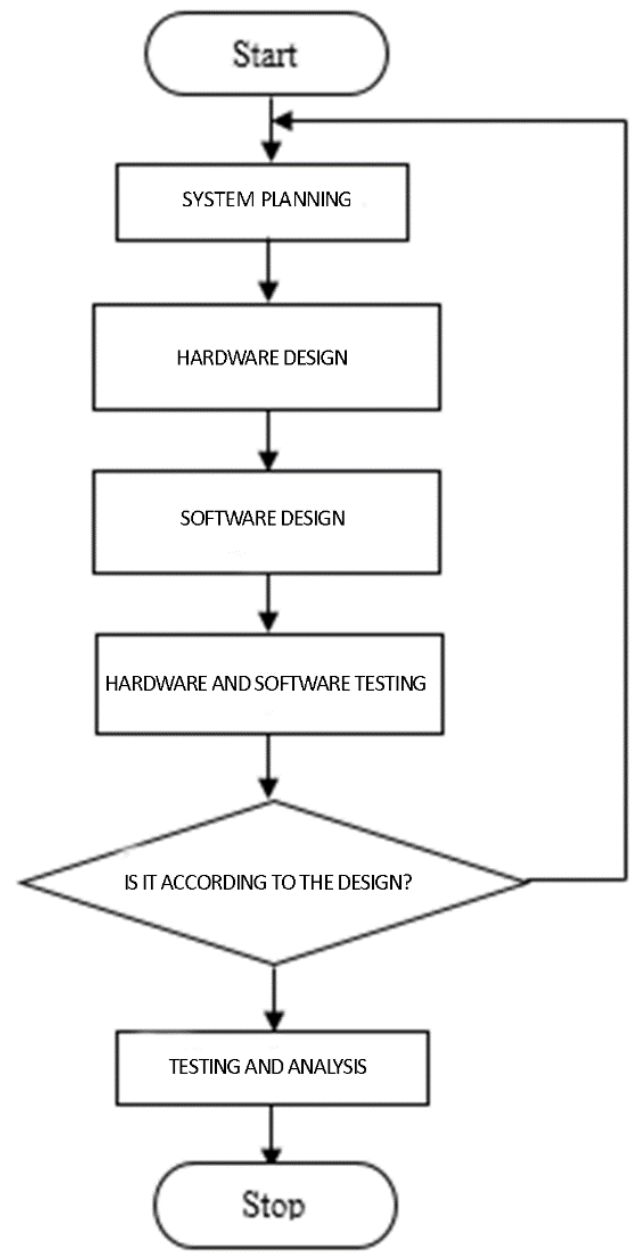

FIGURE 1. Research Flowchart

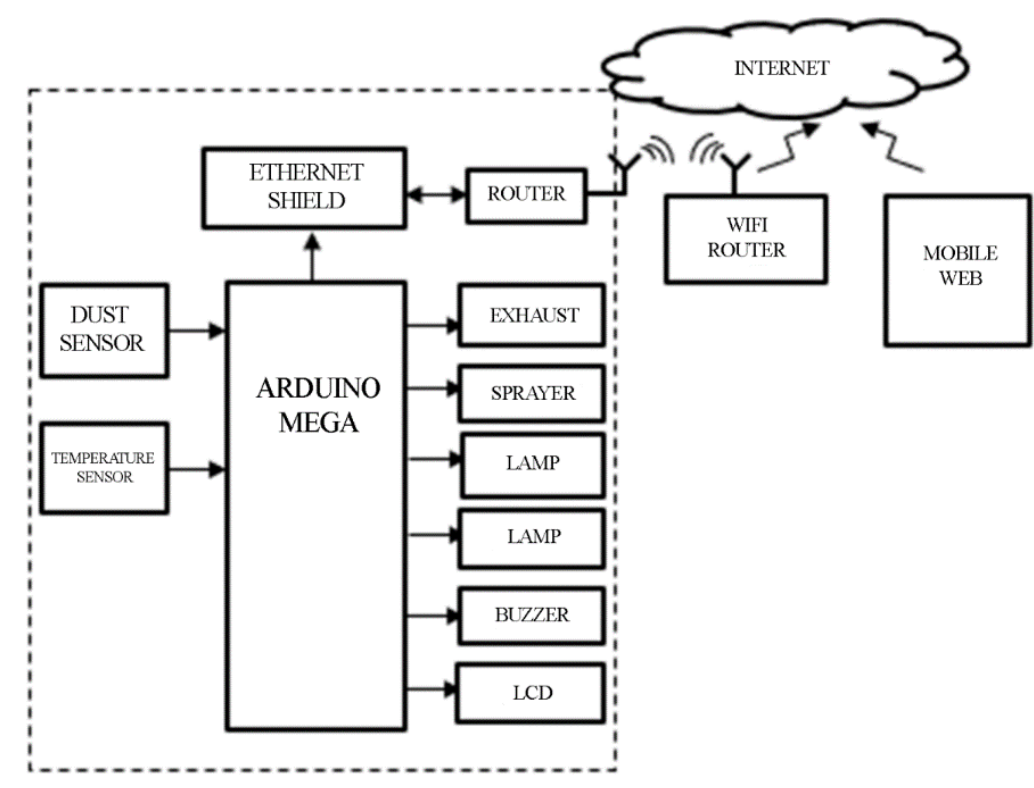

FIGURE 2. System Block Diagram 
Furthermore, as an output of this system by using several outputs such as to neutralize the temperature so that it remains at normal temperatures by using the exhaust fan and using a sprayer to neutralize dust. Indicators using two lamps, lamp 1 is used as an indicator if the dust in the room exceeds a predetermined threshold of $0.15 \mathrm{mg} / \mathrm{m}^{3}$, and for indicator 2 is used as a temperature indicator if it exceeds a predetermined threshold of $35^{\circ} \mathrm{C}$.

In this system, there is also a buzzer as an indicator to provide information to users if the dust and temperature exceed a predetermined threshold; the buzzer will sound. Then a $16 \times 2 \mathrm{LCD}$ is used to display dust and temperature data in the room. Besides using LCD, the data display can be seen through the mobile web using a smartphone because this system is supported by the use of the Internet of Things. In addition to displaying data on a mobile web application that can be viewed through a smartphone by utilizing the internet network, the application can also control the sprayer so that it can activate the exhaust fan and sprayer to neutralize the room without waiting past a predetermined threshold.

\section{SOFTWARE DESIGN}

Software design is designing a set of electronic data in the form of a program or instruction that will execute an order. In this research, Arduino IDE software is used to program the Arduino board. Arduino IDE has the advantage of very easy to make programs because it uses $\mathrm{C}$ or $\mathrm{C}++$ languages. Besides, Arduino IDE provides a simple integrated platform that can run on a personal computer (PC or laptop) [18], for the appearance of data in the form of the mobile web using HTML, CSS, and PHP languages and supported by MySql databases that are encoded using Notepad++ software.

\section{HARDWARE AND SOFTWARE TESTING}

Testing is done to ensure the system runs well. Tests carried out on several modules and components used such as dust sensor testing, which is done by measuring the level of dust in the room with two (2) categories, namely the first category of measurements in the room with clean air that has a value $<15 \mathrm{mg} / \mathrm{m}^{3}$, then testing is carried out at a dirty/smoky room that has a value $>15 \mathrm{mg} / \mathrm{m}^{3}$. As a validation of the prototype that has been made, especially in testing the dust sensor, then we compare the data using a nephelometer.

Furthermore, testing the temperature sensor used is DHT 22. Testing is done by placing a prototype in the room, and the results of the data obtained by the DHT 22 sensor are validated by comparing the data with a thermometer.

Next, test the success rate of the tool. Tests carried out by inserting a prototype into a box made of acrylic with a size of $55 \mathrm{~cm}$ x $45 \mathrm{~cm}$, which is considered as a room. Inside the box is protected by a dust sample using a vacuum sprayer/vacuum blower. Then prepare the stopwatch to find out how long the prototype can neutralize the dusty room.

\section{RESULT AND DISCUSSION}

The results and discussion of the Internet of Things (IoT) indoor air quality monitoring system are as follows. 


\section{Description of Research Results}

Based on the block diagram and flowchart that has been designed, the researcher implements in the form of a prototype of an indoor air quality monitoring system based on the internet of things as in FIGURE 3 below.

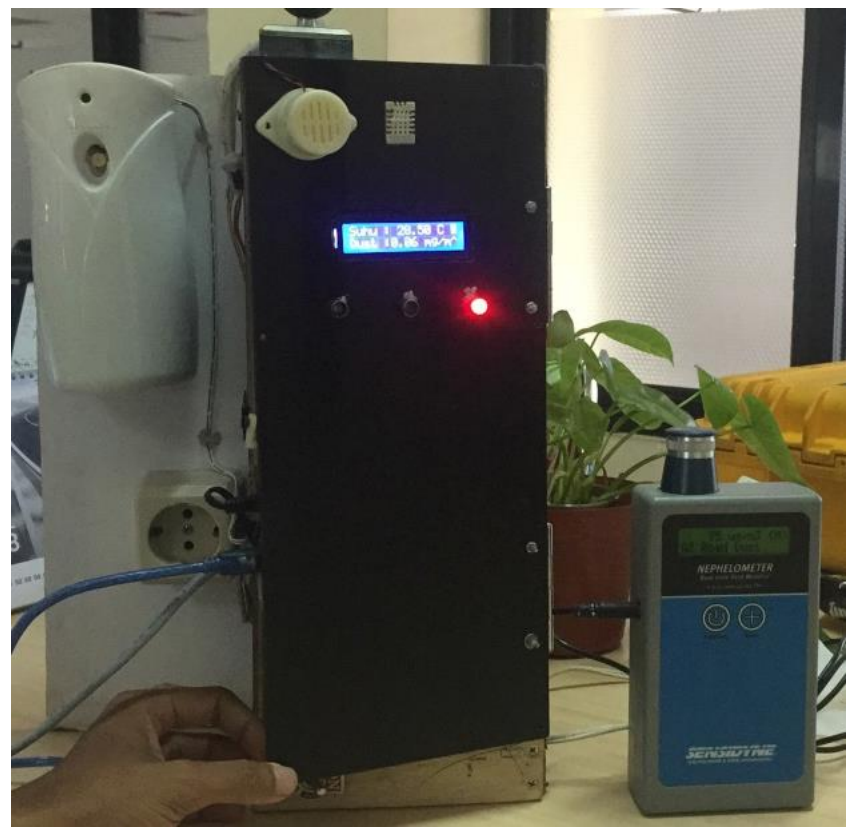

FIGURE 3. Implementation on the prototype

And as already explained that this system is based on the internet of things (IoT) so that it can be controlled using the internet network, and FIGURE 4 below is a display of the web interface as an interface for remote monitoring and a sprayer controller for both temperature and dust.

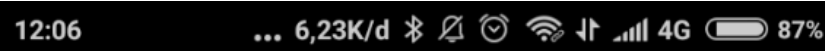

smkbinamandiri.net/agunk/ :

Monitoring Ruangan

Suhu $=34.2 \mathrm{CAman}$
Debu $=0.12 \mathrm{~m} / \mathrm{g} A \operatorname{man}$

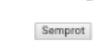

FIGURE 4. Interface System On The Web

\section{Dust Sensor Testing}

In testing the dust, the sensor is done by measuring the level of dust in the room with two categories, namely:

1. Measurement of clean air that has a value $<0.15 \mathrm{mg} / \mathrm{m}^{3}$.

2. Measurement of dirty / dusty air which has a value $>0.15 \mathrm{mg} / \mathrm{m}^{3}$. 
The measurement refers to the data in the sensor datasheet, as shown in FIGURE 5.

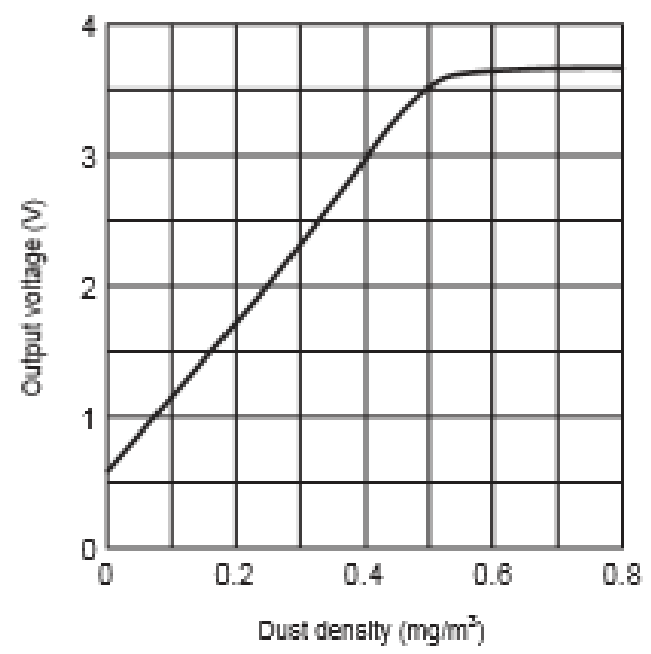

FIGURE 5. Graphical dust sensor datasheet

And as shown in FIGURE 5, the dust density is compared with the sensor reading voltage, as shown in TABLE 1 . The greater the dust density, the greater the voltage required.

TABLE 1. Testing the Dust Sensor by Referring to the Sensor Datasheet

\begin{tabular}{lll}
\hline Device Condition & $\begin{array}{l}\text { The value read on the sensor } \\
(\mathrm{mg} / \mathrm{m} 3)\end{array}$ & $\begin{array}{l}\text { Voltage value } \\
(\mathrm{V})\end{array}$ \\
\hline Udara Bersih $<0.15 \mathrm{mg} / \mathrm{m} 3$ & 0.06 & 1 \\
Udara asap/debu $>0.15 \mathrm{mg} / \mathrm{m} 3$ & 0.53 & 3.3 \\
\hline
\end{tabular}

Furthermore, the dust sensor test chart from TABLE 1 above, as shown in FIGURE 6.

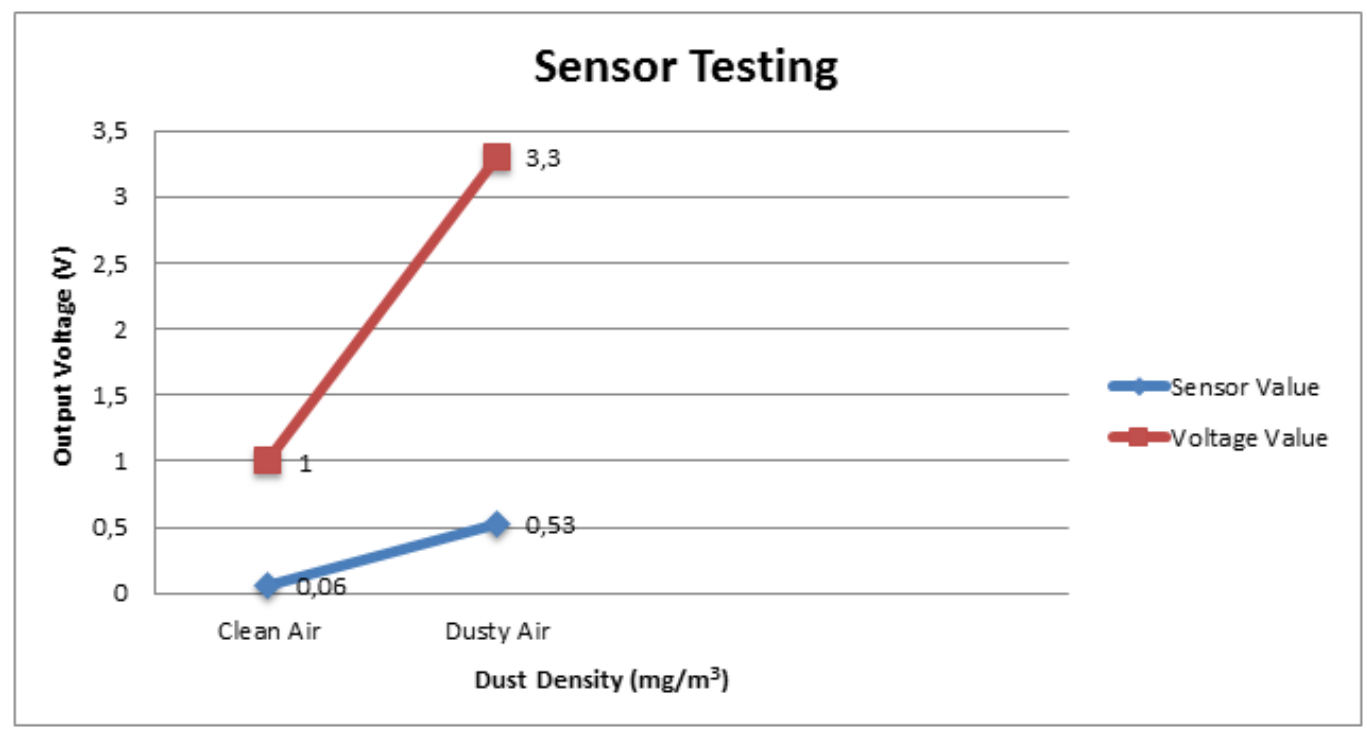

FIGURE 6. Sensor Testing 
From the sensor test results shown in FIGURE 6 above, it is known that the sensor can run well, wherein clean air conditions, the sensor value shows the number $<0.15 \mathrm{mg} / \mathrm{m}^{3}$ precisely at the figure $0.06 \mathrm{mg} / \mathrm{m}^{3}$. Furthermore, when tested on dusty air, the sensor value indicates the number $>0.15 \mathrm{mg} / \mathrm{m}^{3}$ precisely at $0.53 \mathrm{mg} / \mathrm{m}^{3}$. And in accordance with the data in the datasheet shown in FIGURE 5 shows that the dust density is directly proportional to the voltage output value. If the dust density is higher than before, it requires a greater voltage.

\section{Validation of Dust Measurement Testing in an Air Quality Monitoring System with a Nephelometer}

Testing is done by comparing the prototype measuring instrument and a calibrated tool, namely with a Nephelometer, to measure the accuracy and error of dust in the room. The error value can be calculated with the following equation:

$$
\text { Error value }=\frac{\text { Prototype value }- \text { Thermometer Value }}{\text { Prototype }} \times 100 \%
$$

Moreover, accurate values can be calculated with the following equation:

$$
\text { Accuracy Value }=100 \% \text { - error }
$$

Furthermore, in FIGURE 7 below shows the results of testing dust measurements using the Air Quality Monitoring System compared to using a Nephelometer.

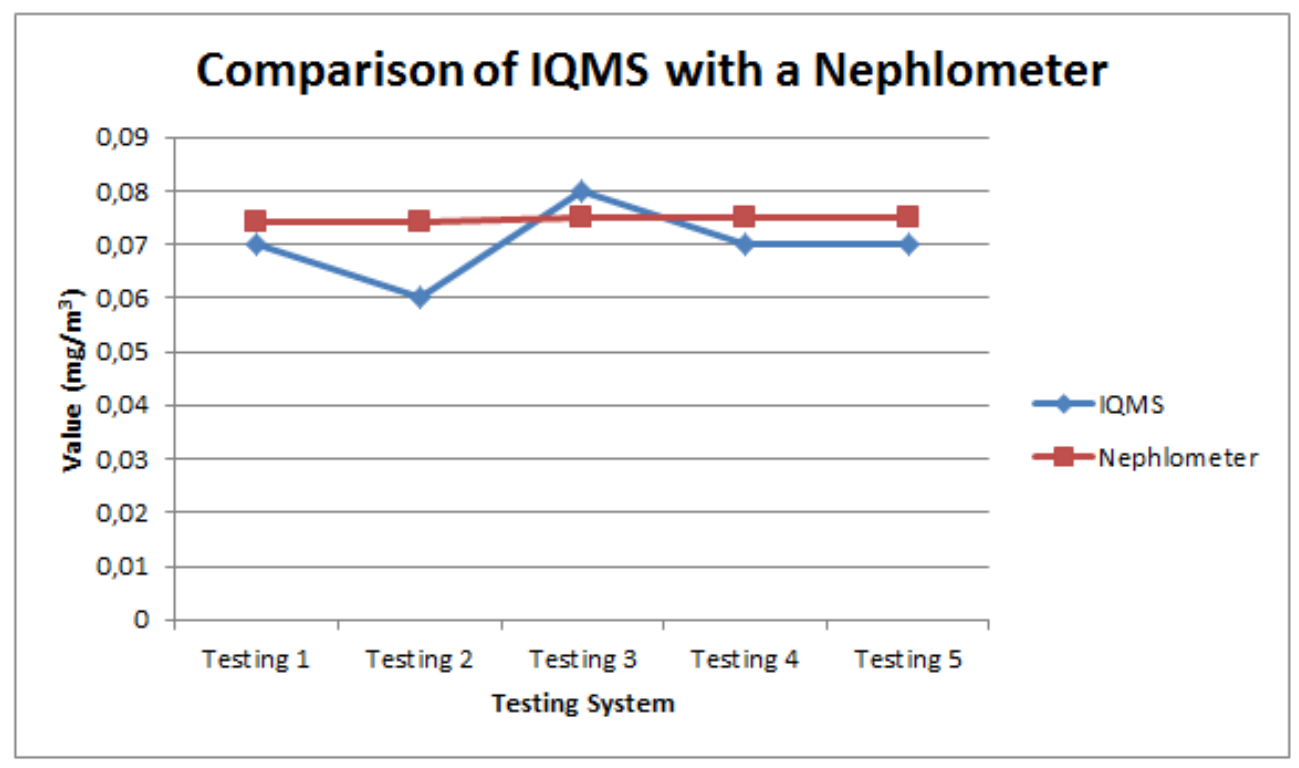

FIGURE 7. Comparison of IQMS with a Nephelometer 
From the picture above, we can see that the value shown on IQMS is not much different from the value shown on the nephelometer. From the data above, the average value of the percentage of errors produced is $12 \%$. This shows that the IQMS system has a good performance in monitoring existing dust.

\section{Temperature Sensor Testing}

Testing the DHT22 sensor as input is done by measuring the level of accuracy and temperature errors calculated by the DHT22 sensor when the sensor is active with a Thermometer. The error value can be calculated with the following EQUATION (1) and (2).

$$
\text { Error Value }=\frac{\text { Prototype Value- Thermometer Value }}{\text { Prototype }} \times 100 \%
$$

Moreover, accurate values can be calculated with the following equation:

$$
\text { Accuracy Value }=100 \%-\text { error }
$$

Test analysis and graphs can be seen in FIGURE 8.

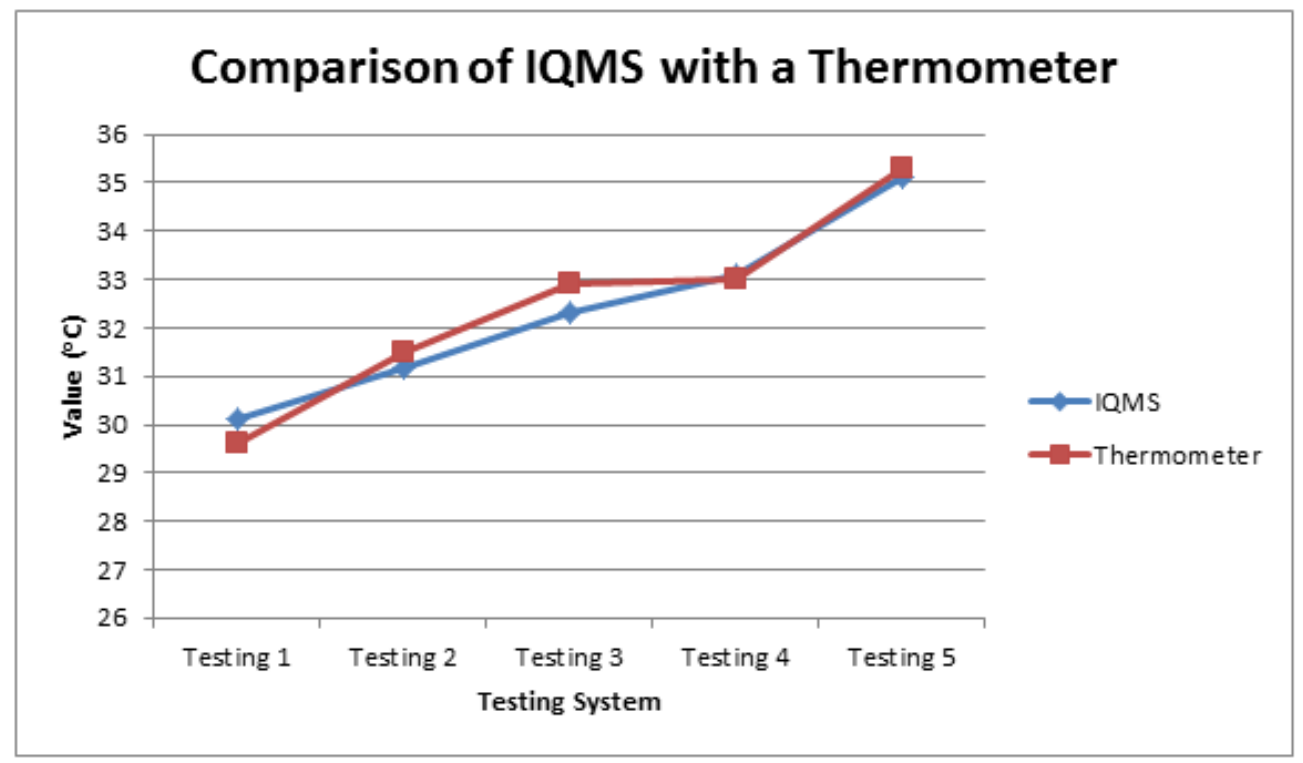

FIGURE 8. Comparison of IQMS with a Thermometer

From the picture above, it can be concluded that there is no significant difference between IQMS using the DHT22 sensor and the thermometer. From the above test, the average value of the error percentage of $1.06 \%$. From these data, it can be said that the temperature sensor used on IQMS has good accuracy in monitoring room temperature. 


\section{CONCLUSION}

The prototype of the Air Quality Monitoring system used for research has been developed and works well. This system is based on IoT, where dust and temperature monitoring can be done remotely using a smartphone connected to the internet through the website address smkbinamandiri.net/agunk. This indoor air quality monitoring system refers to S.K. MENKLH No. Kep.02 / MENKLH / 1988, which states that the dust threshold in the room is $0.15 \mathrm{mg} / \mathrm{m}^{3}$, and the temperature is $35^{\circ} \mathrm{C}$. When the situation in the room has dirty/dusty air with a temperature above a predetermined threshold, the output of the sprayer, buzzer, and the active LED indicates the danger/unsafe state.

For monitoring air quality from dust, this system can monitor with a value of $0.00-0.53$ $\mathrm{mg} / \mathrm{m}^{3}$. Indoor air can be categorized into 2 , namely the first category has a value of $0.01-$ $0.15 \mathrm{mg} / \mathrm{m}^{3}$ to express clean air, and the second category has a value of $0.15-0.53 \mathrm{mg} / \mathrm{m}^{3}$ to express dirty/dusty air. Moreover, to find out the level of accuracy of this system, researchers made comparisons between systems made with a Nephelometer. From some of the tests conducted to get an average percentage error of $12 \%$, it can be said that the dust monitoring system in the room has a good accuracy value, and the conditions in the room have clean air. This system can also control the temperature in the room with the specifications; if the temperature has a value of $16-35^{\circ} \mathrm{C}$ then it is declared normal, and if the temperature is $>35^{\circ} \mathrm{C}$ then the temperature is declared hot/dangerous. To find out the accuracy of this system, the researchers made a comparison with the thermometer and obtained an average error value of $1.06 \%$. It can be concluded that the sensor can work well, and the temperature in the room has a normal temperature.

\section{REFERENCES}

[1] J. Y. Kim, C. H. Chu and S. M. Shin, "ISSAQ: An integrated sensing systems for realtime indoor air quality monitoring," IEEE Sensors Journal, 2014, vol. 14.

[2] S. Bhattacharya, S. Sridevi and R. Pitchiah, "Indoor air quality monitoring using wireless sensor network," 2012 Sixth International Conference on Sensing Technology (ICST), 2012.

[3] S. M. Saad et al., "Indoor air quality monitoring system using wireless sensor network (WSN) with web interface," 2013 International Conference on Electrical, Electronics and System Engineering (ICEESE), 2013.

[4] K. A. Y. Ardam, "Relationship of Dust Exposure and Long Exposure with Lungs Faal Interference of Overhaul Power Plant Workers," The Indonesian Journal of Occupational Safety and Health, 2017, vol. 4.

[5] Z. Pan, L. Mølhave and S. K. Kjaergaard, "Effects on eyes and nose in humans after experimental exposure to airborne office dust," Indoor air, 2000, vol. 10.

[6] A. M. Farmer, "The effects of dust on vegetation-a review," Environmental pollution, 1993, vol. 79.

[7] M. Schwartz, "Encyclopedia and handbook of materials, parts and finishes," CRC press, 2016. 
[8] Menkes, "Health Requirements for Office and Industrial Work Environment," ed: Keputusan Menteri Kesehatan RI Nomor, 2002.

[9] M. Ilyas and I. Mahgoub, "Smart Dust: Sensor network applications, architecture and design," CRC press, 2018.

[10] C. A. Alves et al., "Indoor air quality in two university sports facilities," Aerosol and air quality Research, 2013, vol. 13.

[11] J. Li et al., "Wireless sensor network for indoor air quality monitoring," Sensors \& Transducers, 2014, vol. 172.

[12] N. Marchetti et al., "A campus sustainability initiative: Indoor air quality monitoring in classrooms,” 2015 XVIII AISEM Annual Conference, 2015.

[13] R. Weyers et al., "Low-cost Indoor Air Quality (IAQ) Platform for Healthier Classrooms in New Zealand: Engineering Issues," 2017 4th Asia-Pacific World Congress on Computer Science and Engineering (APWC on CSE), 2017.

[14] S. Jangid and S. Sharma, "An embedded system model for air quality monitoring," 2016 3rd International Conference on Computing for Sustainable Global Development (INDIACom), 2016.

[15] A. H. Saptadi, "Perbandingan Akurasi Pengukuran Suhu dan Kelembaban Antara Sensor DHT11 dan DHT22," Jurnal Infotel, 2014, vol. 6.

[16] A. Wahyudi and S. Agoes, "Implementation of Grating Machine Automation Using Arduino Mega 2560 Microcontroller,” TESLA: Jurnal Teknik Elektro,2017, vol. 18.

[17] M. Kusriyanto and B. D. Putra, "Smart home using local area network (LAN) based arduino mega 2560," 2016 2nd International Conference on Wireless and Telematics (ICWT), 2016.

[18] L. Louis, "Working Principle of Arduino and Using IT," Int. J. Control. Autom. Commun. Syst,2016, vol. 1. 
